\title{
Risk factors associated with gonorrhea and chlamydia transmission in selected health facilities in Ghana
}

\author{
Helena Dela ${ }^{1 *} \mathbb{D}$, Naiki Attram², Eric Behene', Selassie Kumordjie” ${ }^{1}$ Kwasi Kennedy Addo ${ }^{1}$, Edward Owusu Nyarko ${ }^{3}$, \\ Nicholas N. A. Kyei ${ }^{3}$, John Nii Ayite Carroll ${ }^{4}$, Cynthia Kwakye ${ }^{5}$, Christopher Anthony Duplessis ${ }^{6}$, Nehkonti Adams ${ }^{6}$, \\ Eric Garges ${ }^{7}$ and Andrew Gordon Letizia ${ }^{2}$
}

\begin{abstract}
Background: Understanding the underlying epidemiology that shapes Neisseria gonorrhoeae (GC), and Chlamydia trachomatis (CT) infections can contribute to data driven policies directed towards curbing the proliferation of these pathogens in Ghana. Information on the symptoms and risk factors for STIs will help to identify high-risk individuals which will in turn inform STI syndromic management and tailor the use of public health resources.

Methods: Participants were from 4 military clinics and 1 civilian STI clinic in Ghana and eligible if they had symptoms suggestive of STI. First void urine samples were collected and tested with Nucleic Acid Amplification Test (NAAT). A structured questionnaire was administered to all participants. Multivariate logistic regression identified factors associated with infection, separately for NG and for $C T$ and for men and women.

Results: A total of 950 patients, $58 \%$ of whom were females were enrolled, $28 \%$ had gonorrhea and $11 \%$ had chlamydia with more males testing positive than females. Reported symptoms that were more common among patients who tested positive for gonorrhea were painful urination and urethral discharge (all $P$ values $<0.05$ ). Additionally, multiple sexual partners and alcohol use were statistically associated with higher rates of gonorrhea in males while only the frequency of condom use was associated with gonorrhea for females. None of the symptoms or risk factors except marital status was associated with testing positive for chlamydia.

Conclusion: Identifying these symptoms and risk factors help inform health care delivery systems for STIs in Ghana. Furthermore, men and women presenting with these symptoms and risk factors are a prime target for public health education campaigns, aimed at curbing the spread of gonorrhea and chlamydia infections.
\end{abstract}

Keywords: Gonorrhea, Chlamydia, Ghana, Risk factors, STIs

\section{Background}

More than one million sexually transmitted infections (STIs) are acquired globally everyday [1]. These include common treatable STI pathogens such as Treponema pallidium, Neisseria gonorrhoeae, Chlamydia trachomatis and Trichomonas vaginalis. The largest disease burden occurs in developing nations within South and South-East Asia, followed by Sub-Saharan Africa [2]. N. gonorrhea and $C$. trachomatis comprise the most common bacterial STIs globally and can present as co-infections. This is of

\footnotetext{
* Correspondence: helena.ogum@gmail.com

${ }^{1}$ Noguchi Memorial Institute for Medical Research (NMIMR), Legon, Ghana Full list of author information is available at the end of the article
}

particular concern in Sub-Saharan Africa since both of these infections can potentiate HIV infection exacerbating the epidemic on the continent $[3,4]$. In females, symptoms can include abnormal vaginal discharge, dysuria, dyspareunia, hematuria, and lower abdominal pain. However, these symptoms are frequently absent, contributing to delayed treatment and further transmission. Untreated, these infections predispose females to ectopic pregnancy and can cause Pelvic Inflammatory Disease (PID), infertility, and chronic pelvic pain as well as blindness and pneumonia in neonates. Males typically present with penile discharge and/or dysuria, which may lead to complications including penile stricture, epididymoorchitis, and

(c) The Author(s). 2019 Open Access This article is distributed under the terms of the Creative Commons Attribution 4.0 International License (http://creativecommons.org/licenses/by/4.0/), which permits unrestricted use, distribution, and reproduction in any medium, provided you give appropriate credit to the original author(s) and the source, provide a link to the Creative Commons license, and indicate if changes were made. The Creative Commons Public Domain Dedication waiver (http://creativecommons.org/publicdomain/zero/1.0/) applies to the data made available in this article, unless otherwise stated. 
sterility. These chronic complications can have a profound negative effect on the individual and the public health of a nation. Gonorrhea and chlamydia significantly contribute to elevated disability adjusted life years (DALYs) [5-7].

The Ghanaian Ministry of Health guidelines for STI management utilizes the WHO recommended syndromic approach to patient evaluation and treatment due to the lack of cost-effective laboratory tests [8-10]. Syndromic management is an approach in which clinical algorithms for commonly presenting signs and symptoms (e.g., painful urination and urethral discharge) are used to define cases [11]. In low resource settings, the syndromic approach can be used as a tool to aid diagnosis, and treat STIs.

Data on the overall incidence of gonorrhea and chlamydia in individuals presenting with symptoms consistent with STIs in Ghana is limited. Most saliently $N$. gonorrhea and chlamydia risk factors may be vastly different in Ghana than in other geographical locales (including in Sub-Saharan Africa) as they are influenced by economic factors, indigenous norms, and sociocultural influences that are different than other areas, especially the developed-world. Sexual and reproductive healthcare in Ghana will improve with more efficient case detection and better prevention strategies $[9,12]$.

The aim of this study was to identify factors associated with gonorrhea and chlamydia infection and determine the prevalence of both diseases in symptomatic individuals. This information will provide insight on which populations are most at risk of acquiring gonorrhea or chlamydia allowing for data driven decisions concerning which population groups should be targeted for use of limited diagnostic capacity, screening programs, treatment strategies, and targeted public health educational campaigns within Ghana.

\section{Methods}

Surveillance was performed in two military clinics in Takoradi, one in Sekondi, one at the 37 Military Hospital, as well as the civilian Adabraka STI clinic in Ghana. Patients seeking care at the selected clinics with symptoms consistent with urethritis or cervicitis between June 2012 and March 2016 were approached for consenting and enrollment. Inclusion criteria included urethral discharge or dysuria in men as well as vaginal discharge, intermenstrual bleeding, or abdominal pain in women. Exclusion criteria were volunteers unable to provide consent, patients less than 12 years of age, had already participated in the study, or those without an STI syndrome or suspicion of gonorrhea.

Eligible patients were made to provide a written informed consent before enrollment. During the consenting process, all eligible patients provided a urine specimen and completed a structured questionnaire
[13-15] and then had the option of providing a urethral/ endocervical swab for culture as well. Details of the laboratory methods used in this study have been described elsewhere [16].

Ethical approval was received from the Naval Medical Research Unit Number 3, Cairo, Egypt with an approval number of NAMRU3.2012.0007.

\section{Laboratory analysis}

Nucleic Acid Amplification Testing (NAATs) was performed for both gonorrhea and chlamydia on DNA extracts from urine samples. The LightMix ${ }^{\circ}$ kit was used to detect both Neisseria gonorrhea and Chlamydia trachomatis DNA (TIB MOLBIOL, Berlin, Germany) using the LightCycler 480II (Roche Diagnostics, Germany) according to the manufacturer's instructions.

\section{Statistical analysis}

Preliminary analysis was done using basic descriptive statistics in which frequency and percentage were applied to describe the laboratory outcome (gonorrhea and chlamydia infection) and independent variables. Chi-square and Fishers exact test were used where appropriate to determine the association between the outcome and independent variables stratified by gender. The significance level was set at a $p$-value $<0.05$. Variables which had $\mathrm{p}$-value $<0.2$ were selected and fitted into a multivariable logistic regression. Final model was determined using a stepwise backward selection method, removing the least significant variable and re-computing until all remaining variables were significant $(p<0.05)$. Five variables were forced into the final model after they were dropped during the variable selection process because they were considered as a priority potential predictor for STI infection. These were age, marital status, alcohol intake, condom usage and more than one sexual partner in the past month. Results were reported with odds ratio (OR) with $95 \% \mathrm{CI}$. The overall model fit was assessed using the log likelihood ratio [2]. All data analysis was done using STATA version 13.

\section{Results}

A total of nine hundred and fifty participants comprising $58 \%$ females and $42 \%$ males were enrolled (Table 1 ). The most frequent age group (42\%) was 25-31 year-olds, $37 \%$ were married and a majority $(96 \%)$ of them had some form of formal education. Overall, the proportion of participants who tested positive for either gonorrhea or chlamydia was $28 \%$ (95\% CI: $24.8-30.6$ ) and $11 \%$ (95\% CI: 9.3-13.3), respectively. Males were more likely to test positive for gonorrhea and chlamydia than females $(43.1 \%$ vs. $16.4 \%, P<0.001)$ and $(15.2 \%$ vs. $8.2 \%$, $P<0.001)$ respectfully. Eighty-nine $(25.3 \%)$ married participants tested positive for gonorrhea, while 174 (29.1\%) 
Table 1 Demographic and Social behavioral Characteristics of Patients with Gonorrhea (GC) or Chlamydia (CT)

\begin{tabular}{|c|c|c|c|c|c|c|c|c|c|c|}
\hline \multirow[t]{2}{*}{ Variable } & \multicolumn{5}{|l|}{ Male } & \multicolumn{5}{|l|}{ Female } \\
\hline & $\begin{array}{l}\text { Tested } \\
(N=401)\end{array}$ & $\begin{array}{l}\mathrm{GC}+\mathrm{ve} \\
\mathrm{n}(\%)\end{array}$ & $P$-value & $\begin{array}{l}\mathrm{CT}+\mathrm{ve} \\
\mathrm{n}(\%)\end{array}$ & $P$-value & $\begin{array}{l}\text { Tested } \\
(N=549)\end{array}$ & $\begin{array}{l}\mathrm{GC}+\mathrm{ve} \\
\mathrm{n}(\%)\end{array}$ & $P$-value & $\begin{array}{l}C T+v e \\
\mathrm{n}(\%)\end{array}$ & $P$-value \\
\hline Age group(years) ${ }^{a}$ & & & 0.033 & & 0.119 & & & 0.500 & & 0.078 \\
\hline $18-24$ & 103 & $43(41.8)$ & & $11(10.7)$ & & 153 & $28(18.3)$ & & $19(12.42)$ & \\
\hline $25-31$ & 177 & $86(48.6)$ & & 33(18.6) & & 226 & $40(17.7)$ & & $20(8.9)$ & \\
\hline $32-38$ & 71 & $31(43.7)$ & & 13(18.3) & & 113 & $17(15.0)$ & & $5(4.4)$ & \\
\hline $39-45$ & 30 & $6(20.0)$ & & $4(13.3)$ & & 41 & $4(9.8)$ & & $1(2.4)$ & \\
\hline 46 and above & 18 & $5(27.8)$ & & $0(0.0)$ & & 16 & $1(6.3)$ & & $0(0.0)$ & \\
\hline Marital status & & & 0.767 & & 0.748 & & & 0.537 & & 0.036 \\
\hline Single & 289 & 126(43.6) & & $45(15.7)$ & & 309 & $48(15.5)$ & & $33(10.4)$ & \\
\hline Married & 112 & $47(42.0)$ & & $16(14.3)$ & & 240 & $42(17.5)$ & & $13(5.4)$ & \\
\hline Educational level & & & 0.873 & & 0.234 & & & 0.496 & & 0.114 \\
\hline No education & 15 & $7(46.7)$ & & $0(0.0)$ & & 23 & $4(17.4)$ & & $0(0.0)$ & \\
\hline Primary/JHS & 66 & $27(40.9)$ & & $9(13.6)$ & & 95 & $19(20.0)$ & & $12(12.6)$ & \\
\hline Secondary and above & 320 & $140(43.4)$ & & $52(16.3)$ & & 431 & $67(15.6)$ & & $33(7.7)$ & \\
\hline Alcohol intake & & & 0.021 & & 0.344 & & & 0.511 & & 0.308 \\
\hline Yes & 180 & $89(49.4)$ & & 24(13.3) & & 114 & $21(18.4)$ & & $12(10.5)$ & \\
\hline No & 221 & $84(38.0)$ & & $37(16.7)$ & & 435 & $69(15.9)$ & & $33(7.6)$ & \\
\hline Use of condoms ${ }^{a}$ & & & 0.455 & & 0.471 & & & 0.052 & & 0.538 \\
\hline Never & 135 & $61(45.2)$ & & 19(14.1) & & 245 & $46(18.8)$ & & $24(9.8)$ & \\
\hline Rarely & 109 & $50(45.9)$ & & 13(11.9) & & 137 & $26(19.0)$ & & $11(8.0)$ & \\
\hline On most occasion & 75 & $34(45.3)$ & & 14(18.7) & & 73 & $9(12.3)$ & & $5(6.9)$ & \\
\hline Always & 74 & $26(35.1)$ & & 14(18.9) & & 66 & $4(6.1)$ & & $3(4.6)$ & \\
\hline $\begin{array}{l}\text { Having more than one sexual } \\
\text { partner in the past month }\end{array}$ & & & 0.000 & & 0.474 & & & 0.884 & & 0.252 \\
\hline Yes & 86 & $53(61.6)$ & & $11(12.8)$ & & 29 & $5(17.2)$ & & $4(13.8)$ & \\
\hline No & 314 & $104(45.4)$ & & 50(15.9) & & 512 & $83(16.2)$ & & $40(7.8)$ & \\
\hline
\end{tabular}

GC Gonorrhea, CT Chlamydia

a $V$ ariables with asterisk had missing responses, which ranged from $n=2$ to 36

unmarried participants tested positive for the infection. Chlamydia rates were higher among unmarried participants (13.0\%) than married participants (8.2\%) which was statistically significant $(p=0.03)$. A total of 31 participants had co-infections with these two pathogens, out of which $81 \%$ were males and $29 \%$ females.

Regarding sexual practices of the participants, 380 (40.0\%) reported never using condoms while 570 (60.0\%) used a condom at least once. Among the 115 study participants (12.2\%) who reported having more than one sexual partner in the past month, $82(71.3 \%)$ tested positive for gonorrhea and 15 (13.0\%) tested positive for chlamydia. Among males, there was a significant difference in gonorrhea rates between those who reported more than one sexual partner in the past month and those who had not, $62 \%$ versus $45 \%(p<0.001)$. The rates of gonorrhea infections between females with multiple sexual partners (17\%) compared to those who reported to have only one partner (16\%) did not show any statistical significance. Additionally, there was no difference in the rates of chlamydia infections in men or women with multiple or only a single partner.

Almost a third of the study participants, 294 (30.9\%) reported alcohol intake. Among those who drank alcohol, $200(68.0 \%)$ drank at least once to five times a week, while 94 (32.0\%) drank occasionally. Of those, 110 (37.4\%) tested positive for gonorrhea and 36 (12.2\%) for chlamydia.

Most participants presented with clinical symptoms such as discharge (85.3\%), burning during urination (48.3\%), and penile/vaginal pain (27.9\%) (Table 2). Among males, statistically significant symptoms associated with gonorrhea infection were penile discharge, dysuria and hematuria. However, none of the symptoms was associated with chlamydia for men. Among females, none of the symptoms was significantly associated with gonorrhea or chlamydia.

In the multiple logistic regression, the factors which were significantly related to gonorrhea infection, but not 
Table 2 Clinical Presentation of Patients with Gonorrhea and Chlamydia

\begin{tabular}{|c|c|c|c|c|c|c|c|c|c|c|}
\hline & Male & & & & & Female & & & & \\
\hline & $\begin{array}{l}\text { Total } \\
(N=401)\end{array}$ & $\begin{array}{l}\mathrm{GC}+\mathrm{ve} \\
\mathrm{n}(\%)\end{array}$ & $P$-value & $\begin{array}{l}C T+v e \\
n(\%)\end{array}$ & $P$-value & $\begin{array}{l}\text { Total } \\
(N=549)\end{array}$ & $\begin{array}{l}\mathrm{GC}+\mathrm{ve} \\
\mathrm{n}(\%)\end{array}$ & $P$-value & $\begin{array}{l}C T+v e \\
n(\%)\end{array}$ & $P$-value \\
\hline Variable & & & & & & & & & & \\
\hline Painful Urination & & & 0.001 & & 0.283 & & & 0.856 & & 0.724 \\
\hline Yes & 238 & $119(50.0)$ & & $40(16.8)$ & & 221 & $37(16.7)$ & & $17(7.7)$ & \\
\hline No & 163 & $54(33.1)$ & & 21(12.9) & & 328 & $53(16.2)$ & & $28(8.5)$ & \\
\hline Discharge & & & 0.000 & & 0.270 & & & 0.952 & & 0.146 \\
\hline Yes & 321 & 153(47.7) & & $52(16.2)$ & & 489 & $80(16.4)$ & & $43(8.8)$ & \\
\hline No & 80 & $20(25.0)$ & & $9(11.3)$ & & 60 & $10(16.7)$ & & $2(3.3)$ & \\
\hline Pain in penis or vagina & & & 0.767 & & 0.219 & & & 0.813 & & 0.378 \\
\hline Yes & 112 & $47(42.0)$ & & 21(18.8) & & 153 & $26(17.0)$ & & $10(6.5)$ & \\
\hline No & 289 & 126(43.6) & & $40(13.8)$ & & 396 & $64(16.2)$ & & $35(8.8)$ & \\
\hline Foul smell & & & 0.767 & & 0.763 & & & 0.544 & & 0.101 \\
\hline Yes & 67 & $30(44.8)$ & & $11(16.4)$ & & 161 & $24(14.9)$ & & 18(11.2) & \\
\hline No & 334 & $143(42.8)$ & & $50(15.0)$ & & 388 & $66(17.0)$ & & $27(7.0)$ & \\
\hline Painful sex & & & 0.640 & & 0.764 & & & 0.474 & & 0.629 \\
\hline Yes & 23 & $11(47.8)$ & & $4(17.4)$ & & 107 & $20(18.7)$ & & $10(9.4)$ & \\
\hline No & 378 & 162(42.9) & & $57(15.1)$ & & 442 & $70(15.8)$ & & $35(7.9)$ & \\
\hline Bleeding from Penis or vagina & & & 0.024 & & 0.501 & & & 0.424 & & 0.647 \\
\hline Yes & 12 & $9(75.0)$ & & $1(8.3)$ & & 60 & $12(20.0)$ & & $4(6.7)$ & \\
\hline No & 389 & 144(42.2) & & $60(15.4)$ & & 489 & $78(16.0)$ & & $41(8.4)$ & \\
\hline Genital itching & & & 0.304 & & 0.527 & & & 0.392 & & 0.833 \\
\hline Yes & 42 & 15(35.7) & & $5(11.9)$ & & 129 & $18(14.0)$ & & 10(7.8) & \\
\hline No & 359 & $158(44.0)$ & & $56(15.6)$ & & 420 & $72(17.1)$ & & $35(8.3)$ & \\
\hline
\end{tabular}

chlamydia, among men included multiple sexual partners in the past month, dysuria and penile discharge (all $P$-values < 0.05). For females, use of condoms during sexual intercourse was the only factor significantly associated with gonorrhea. For women, a combination of these symptoms or demographic variables did not have any statistically significant association either. Females who reported that they or their partners always used condoms during sexual intercourse were less likely to test positive for gonorrhea, as compared to those who never used it (OR, 0.3; 95\% CI, 0.1-0.8) (Table 3). Also, females who were married were less likely to test positive for chlamydia than those who were not married (OR, 0.4; 95\% CI, 0.2-0.9) (Table 4).

\section{Discussion}

In Ghana, the existing published data on gonorrhea and chlamydia prevalence is mainly from women attending gynecological, antenatal or postpartum clinics [17-20]. Some of these studies found higher chlamydia prevalence than gonorrhea, contrary to results obtained in this study $[21,22]$. The lower previously published infection rates of $0-15 \%$ for gonorrhea and $1.5-7 \%$ for chlamydia, could be attributed to different diagnostic methodologies employed and varied patient populations examined in this work. One major difference between our study and others includes using a more sensitive method, NAAT, to diagnose infection. Our study population contained $42 \%$ men who accounted for $66 \%$ of the gonorrhea and $58 \%$ of chlamydia cases. While women, who made up $58 \%$ of the study population, accounted for just $34 \%$ of the gonorrhea and $42 \%$ of the chlamydia cases.

As part of syndromic management, an assessment of risks based upon symptoms as well as demographic, and socioeconomic factors, aids in the clinical detection of STIs and helps direct limited resources to target individuals that are most at risk of having gonorrhoea or chlamydia. In this study, painful urination (50\%) and urethral discharge (48\%) were significantly associated with a diagnosis of gonorrhoea but not chlamydia in men. Therefore, our study results confirm that the syndromic approach may be better if utilized in health centres catering to symptomatic males to diagnose and treat gonorrhoea. Educating the general public on the possible symptoms associated with gonorrhoea would enable 
Table 3 Multiple Logistic regression of gonorrhoea with selected patient characteristics

\begin{tabular}{|c|c|c|}
\hline & \multicolumn{2}{|l|}{ Male Model, $N=398$} \\
\hline & odds Ratio(95\% Cl) & $P$-value \\
\hline \multicolumn{3}{|l|}{ Age group(years) } \\
\hline $18-24$ & 1(Ref) & \\
\hline $25-31$ & $1.3(0.8-2.2)$ & 0.343 \\
\hline $32-38$ & $1.1(0.6-2.0)$ & 0.837 \\
\hline $39-45$ & $0.4(0.1-1.1)$ & 0.069 \\
\hline 46 and above & $0.6(0.2-2.1)$ & 0.462 \\
\hline \multicolumn{3}{|l|}{ Alcohol intake } \\
\hline Yes & $1.4(0.9-2.2)$ & 0.106 \\
\hline No & 1(Ref) & \\
\hline \multicolumn{3}{|c|}{ Having more than one sexual partner in the past month } \\
\hline Yes & $2.3(1.3-3.8)$ & 0.002 \\
\hline No & 1(Ref) & \\
\hline \multicolumn{3}{|l|}{ Painful urination } \\
\hline Yes & $2.1(1.4-3.3)$ & 0.001 \\
\hline No & 1(Ref) & \\
\hline \multicolumn{3}{|l|}{ Discharge } \\
\hline Yes & $2.3(1.3-4.2)$ & 0.005 \\
\hline No & 1 (ref) & \\
\hline \multicolumn{3}{|c|}{ Bleeding from Penis or Vagina } \\
\hline Yes & $3.0(0.8-12.1)$ & 0.117 \\
\hline No & 1 (ref) & \\
\hline \multicolumn{3}{|l|}{ Female Model, $N=521$} \\
\hline \multicolumn{3}{|l|}{ Use of Condom } \\
\hline Never & 1 (ref) & \\
\hline On most occasions & $0.6(0.3-1.3)$ & 0.189 \\
\hline Always & $0.3(0.1-0.8)$ & 0.015 \\
\hline
\end{tabular}

those at risk to seek early treatment. However, unlike the correlation observed between symptoms and positive diagnoses for gonorrhoea, we failed to identify any correlation between symptoms and chlamydia infection. A lack of an association with commonly correlated symptoms in the literature, especially for chlamydia could be due to a lack of power since only $15 \%$ of the males and $8 \%$ of the females had a positive NAAT. Perhaps other non-clinical risk factors that are behavioural or epidemiological in nature such as sexual preference, socioeconomic position, exchange sex for money, drug use, and sex with partners abroad would be relevant to improving chlamydia case detection [23].

Although all participants reported some symptoms that could be consistent with STIs, $47.6 \%$ of males and $76.3 \%$ of females who presented did not test positive for either disease (Fig. 1). Potential causes other than gonorrhoea or chlamydia infection include infectious aetiologies (e.g.
Table 4 Multiple logistic regression of chlamydia against selected patient characteristics

\begin{tabular}{|c|c|c|}
\hline & \multicolumn{2}{|c|}{ Female Model, $N=500$} \\
\hline & odds Ratio(95\% Cl) & $P$-value \\
\hline \multicolumn{3}{|l|}{ Age group(years) } \\
\hline $18-24$ & 1 (ref) & \\
\hline $32-38$ & $0.5(0.2-1.4)$ & 0.156 \\
\hline \multicolumn{3}{|l|}{ Marital status } \\
\hline Married & $0.4(0.2-0.9)$ & 0.032 \\
\hline \multicolumn{3}{|l|}{ Use of condom } \\
\hline Never & 1 (ref) & \\
\hline On most occasion & $0.5(0.2-1.4)$ & 0.197 \\
\hline Always & $0.3(0.1-1.1)$ & 0.078 \\
\hline \multicolumn{3}{|c|}{ Having more than one sexual partner in the past month } \\
\hline Yes & $2.3(0.7-7.3)$ & 0.159 \\
\hline No & 1 (ref) & \\
\hline
\end{tabular}

trichomoniasis, candidiasis, mycoplasma genitalium) or non-infectious aetiologies. Given the high sensitivity of the NAAT assay, we speculate that there were likely few false negative tests. Since almost half the men and three-quarters of the women had no symptoms at all, a broad differential diagnosis should be considered by providers caring for patients presenting with symptoms consistent with a STI. Ideally, broad testing to include NAAT for GC and CT as well as for other potential aetiologies such as microscopy, vaginal $\mathrm{pH}$ assessment, or mycoplasma genitalium NAAT would be used if resources are available. This will avoid empiric therapy which exposes the patient to unnecessary antibiotics while fostering resistance among other pathogens. However, often time this is not the case and providers will need to consider empiric therapy for other aetiologies other than GC and CT.

Our survey identified three significant risk factors associated with higher rates of STIs: engaging in multiple sexual partnerships (MSP), inconsistent condom use, and alcohol intake. MSPs, defined as greater than one partner in the past month, are a common practice in certain areas in Ghana, predominantly among males [12]. A greater number of males (21\%) were more likely to report engaging in MSPs than females (5\%) from this study. This difference could reflect social desirability bias with men more likely to report having multiple sexual partners than women. Men with multiple sexual partners had significantly higher prevalence of (62\% vs. $45 \%)$ gonorrhea infection compared to those who did not ( $p$-value $<0.001)$.

The second significant risk factor associated with higher prevalence of gonorrhea was frequency of condom use in women with prevalence of $19 \%$ among those who never used condoms, $17 \%$ for inconsistent use of condoms and $6 \%$ for those who always used them. 


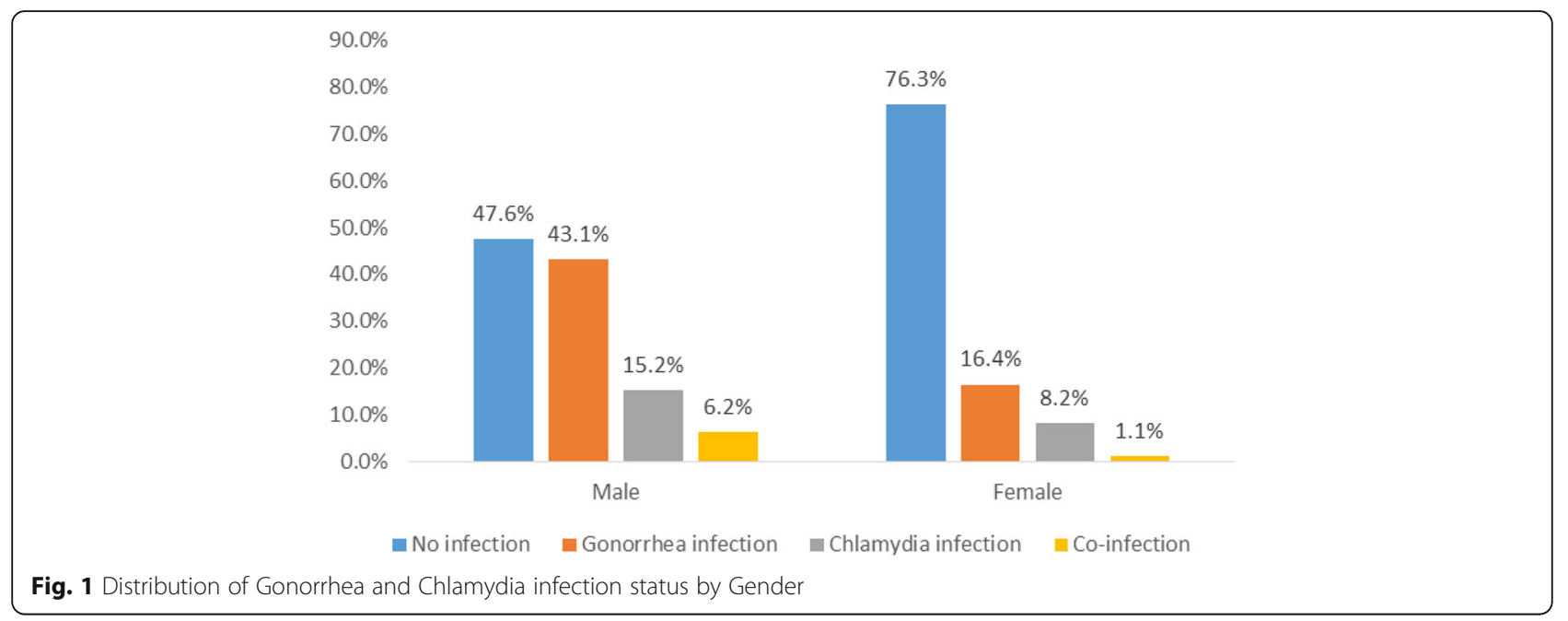

Females who always or even occasionally endorsed using condoms during intercourse have a lower likelihood of having gonorrhea as compared to those who never used condoms (OR, 0.3; 95\% CI, 0.1-0.8). There was no statistically significant relationship between frequency of condom use and prevalence of either gonorrhea or chlamydia in men. Of note, $35 \%$ of men who stated they always use condoms were still positive for gonorrhea compared to a higher rate of $45 \%$ in those who never used condoms and the same held true for chlamydia with rates of $19 \%$ compared to $6 \%$. The high prevalence of gonorrhea identified in males despite a reported compliance with condom usage may reflect recall or social desirability bias. We were unable to pursue repeat evaluations with the respondents that could have helped confirm the validity of the responses and believe this lack of statistical significance is due to the above biases and a lack of power, especially for chlamydia infections.

The third significant risk factor associated with higher rates of gonorrhea was alcohol use. Similar to others studies, men who reported consuming alcohol in this study were more likely to be infected with gonorrhea (49\%) than those who did not (38\%) [24]. Additionally, these individuals had a higher proportion of MSPs than those who did not consume alcohol $(22.5 \%$ versus $7.5 \%$, $\mathrm{p}<0.001)$. This finding supports a previously identified association between alcohol intake and MSPs [25]. A person's judgment can be altered under the influence of alcohol, leading to high-risk sexual behaviors and is a known risk factor for contracting STIs in Africa [26]. Our data supports an association between alcohol intake and having multiple sexual partners leading to high-risk sexual behavior and the acquisition of a gonorrhea infection among males $(p=0.021)$.

Our data identifies three important risk factors to target in STI prevention efforts and to integrate into educational campaigns and clinical history-taking. The association between MSPs, alcohol intake and condom use with higher prevalence of gonorrhea make them high-yield information to obtain while risk stratifying patients who present with symptoms consistent with STI in Ghana. A simple survey instrument composed of just few questions could be easily executed during a clinic visit and help inform subsequent diagnostic testing. Also, they are potential topics for public health campaigns to change behavior among men and women at high risk for STIs.

\section{Conclusions}

Despite the convenience sampling in referral clinics, we have identified a high prevalence of gonorrhea in Ghanaian males as well as risk factors for its acquisition, filling an important gap in knowledge.

Common symptoms significantly associated with gonorrhea among men in Ghana include penile discharge and dysuria. However, none of the common symptoms was significantly associated with chlamydia infection in men. There was no significant association between gonorrhea or chlamydia infection in women and common symptoms. MSPs and alcohol use were statistically associated with higher rates of gonorrhea in males while only the frequency of condom use was associated with gonorrhea in females. None of the risk factors, except marital status was associated with symptomatic chlamydia infection. These risk factors could be elicited upon evaluation of patients by a provider using a simple four question survey to help risk stratify them, better informing a syndromic treatment approach to STIs. The high-risk groups presenting with these risk factors represent a key focus area that needs to be identified by providers for diagnosis and treatment as well as for public health education campaigns. 


\section{Limitations of study}

- This study did not assess for other STIs and other culturally sensitive risk factors such as sexual preference, socioeconomic position, drug use, exchanging sex for money and sex with partners abroad.

- We did not conduct a systematic investigation into the prevalence of either chlamydia or gonorrhea in Ghana. Therefore we are unable to assert actual prevalence figures since by the studies design, it excluded infected but asymptomatic men and women.

- We acknowledge a likelihood of significant recall and social desirability bias inherent in studies looking at STI risk factors that could have influenced our results.

\section{Strengths of study}

- Access to both men and women from five sites. There is a paucity of published information on gonorrhea and chlamydia rates in Ghana, especially among men. Published work on these STIs tend to be gender-biased, with more focus on females than males [20, 21, 27].

We used a more sensitive, specific, and less invasive method (urine NAATs) than has previously been used for diagnosis of gonorrhea (culture and gram stain) and chlamydia.

\section{Abbreviations}

Cl: Confidence interval; CT: Chlamydia trachomatis; DALYs: Disability Adjusted Life Years; DNA: Deoxyribonucleic Acid; GC: Niesseria gonorrhoeae; LR: Likelihood ratio; MSPs: Multiple Sexual Partners; NAAT: Nucleic Acid Amplification Testing; OR: Odds ratio; PID: Pelvic Inflammatory Disease; STIs: Sexually Transmitted Infections

\section{Acknowledgements}

The authors wish to thank the administration and staff of the 37 Military hospital, Adabraka STI clinic and the three Armed Forces sites at Sekondi/ Takoradi who were involved in the study. We also acknowledge the entire staff of the U.S Naval Medical Research Unit number 3, Ghana Detachment for laboratory and technical support.

\section{Funding}

Financial support for this project was provided by GEIS (Global Emerging Infections Surveillance and Response System) Section ProMIS ID P2103_16_N3 funding years 2012-2016. The sponsor of the study had no role in study design, data collection, data analysis, data interpretation, or writing of the report. The corresponding author had full access to all the data in the study and had final responsibility for the decision to submit for publication.

\section{Availability of data and materials}

The datasets used and/or analysed during the current study will be made available from the corresponding author on reasonable request.

\begin{abstract}
Authors' contributions
Conceived and designed the study: NA and CAD. Conducted the study: NA, $H D, E B, S K, K K A, E O N, N N A K, J A C, C K, C A D, N A$. Analyzed the data: EB. Wrote the manuscript: HD, NA, EB, NNAK, JAC, CAD, NA, EG, AGL. All authors read and approved the final manuscript. The author accepts full responsibility for the work and/or the conduct of the study, had access to the data, and controlled the decision to publish. The corresponding author attests that all listed authors meet authorship criteria and that no other, meeting the criteria have been omitted.
\end{abstract}

Ethics approval and consent to participate

Ethical approval was received from the Naval Medical Research Unit Number 3, Cairo, Egypt with an approval number of NAMRU3.2012.0007 in

compliance with all applicable Federal regulations governing the protection of human subjects.

Eligible patients were made to provide a written informed consent before enrollment.

\section{Consent for publication}

Not applicable.

Competing interests

The authors declare that they have no competing interests.

\section{Publisher's Note}

Springer Nature remains neutral with regard to jurisdictional claims in published maps and institutional affiliations.

\section{Author details}

${ }^{1}$ Noguchi Memorial Institute for Medical Research (NMIMR), Legon, Ghana. ${ }^{2}$ US Naval Medical Research Unit 3 Ghana Detachment, Accra, Ghana. ${ }^{3} 37$ Military Hospital, Accra, Ghana. ${ }^{4}$ Airforce Medical Center, Takoradi, Ghana. ${ }^{5}$ Ghana Health Service, Accra, Ghana. ${ }^{6}$ Naval Medical Center, San Diego, USA. ${ }^{7}$ Silver Spring, USA.

Received: 11 July 2018 Accepted: 26 April 2019

Published online: 16 May 2019

References

1. World Health Organization. Sexually Transmitted Infections Fact Sheet. 2015. http://www.who.int/mediacentre/factsheets/fs110/en/. Accessed July 2016.

2. World Health Organization. Global incidence and prevalence of selected curable sexually transmitted infections-2008. World Health Organization; 2012.

3. Johnson LF, Lewis DA. The effect of genital tract infections on HIV-1 shedding in the genital tract: a systematic review and meta-analysis. Sex Transm Dis. 2008:35(11):946-59.

4. Unemo M, Shafer WM. Antimicrobial resistance in Neisseria gonorrhoeae in the 21st century: past, evolution, and future. Clin Microbiol Rev. 2014;27(3): 587-613.

5. Update T. The public health approach to STD control; 1998.

6. Vos T, Flaxman AD, Naghavi M, Lozano R, Michaud C, Ezzati M, et al. Years lived with disability (YLDs) for 1160 sequelae of 289 diseases and injuries 1990-2010: a systematic analysis for the global burden of disease study 2010. Lancet. 2012;380(9859):2163-96.

7. Newman L, Rowley J, Vander HS, Wijesooriya NS, Unemo M, Low N, et al. Global estimates of the prevalence and incidence of four curable sexually transmitted infections in 2012 based on Systematic Review and Global Reporting. PLoS ONE. 2015;10:e0143304

8. Adu-Sarkodie Y, Steiner MJ, Attafuah J, Tweedy K. Syndromic management of urethral discharge in Ghanaian pharmacies. Sexually transmitted infections. 2000;76(6):439-42.

9. Ministry of Health R of G. Standard Treatment Guidelines. 2010. 97-105 p. available from: http://www.moh.gov.gh/wp-content/uploads/2016/02/ Standard-Treatment-Guideline-2010.pdf.

10. World Health Organization. Guidelines for the Management of Sexually transmitted infections. Am J Gastroenterol. 2010;100(September):2324-37. Available from. https://doi.org/10.1016/B978-1-4377-1986-4.00007-X.

11. Bosu WK. Syndromic management of sexually transmitted diseases: is it rational or scientific. Trop Med Int Heal. 1999;4(2):114-9. 
12. Anarfi JK, Awusabo-Asare K. Experimental research on sexual networking in some selected areas of Ghana. Heal Transit Rev. 1993;3:29-43.

13. Alary M, Lowndes CM, Mukenge-Tshibaka L, Gnintoungbé CA, Bedard E, Geraldo N, Jossou P, Lafia E, Bernier F, Baganizi E, Joly JR. Sexually transmitted infections in male clients of female sex workers in Benin: risk factors and reassessment of the leucocyte esterase dipstick for screening of urethral infections. Sexually transmitted infections. 2003;79(5):388-92.

14. Fonck K, Kidula N, Kirui P, Ndinya-Achola J, Bwayo J, Claeys P, et al. Pattern of sexually transmitted diseases and risk factors among women attending an STD referral clinic in Nairobi, Kenya. Sex Transm Dis. 2000;27(7):417-23.

15. Råssjö EB, Mirembe F, Darj E. Self-reported sexual behaviour among adolescent girls in Uganda: reliability of data debated. Afr Health Sci. 2011; 11(3):383-9.

16. Duplessis C, Puplampu N, Nyarko E, Carroll J, Dela H, Mensah A, et al. Gonorrhea surveillance in Ghana, Africa. Mil Med. 2015:180(1):17-22.

17. Bentsi C, Klufio CA, Perine PL, Bell TA, Cles LD, Koester CM, et al. Genital infections with chlamydia trachomatis and Neisseria gonorrhoeae in Ghanaian women. Genitourin Med. 1985;61(March 1984):48-50.

18. Apea-Kubi KA, Yamaguchi S, Sakyi B, Kisimoto T, Ofori-Adjei D, Hagiwara T. Neisseria gonorrhoea, chlamydia trachomatis, and Treponema pallidum infection in antenatal and gynecological patients at Korle-Bu teaching hospital, Ghana. Jpn J Infect Dis. 2004;57(6):253-6.

19. Pepin J, Deslandes S, Khonde N, Kintin DF, Diakite S, Sylla M, Meda H, Sobela F, Asamoah-Adu C, Agyarko-Poku T, Frost E. Low prevalence of cervical infections in women with vaginal discharge in west Africa: implications for syndromic management. Sexually transmitted infections. 2004;80(3):230-5

20. Sylverken AA, Owusu-Dabo E, Yar DD, Salifu SP, Yaa Awua-Boateng N, Amuasi JH, et al. Bacterial etiology of sexually transmitted infections at a STI clinic in Ghana; use of multiplex real time PCR. Ghana Med J 2016;50(503): 142-142. Available from: doi.https://doi.org/10.4314/gmj.v50i3.5

21. Opoku BK, Sarkodie Y. Prevalence of genital chlamydia and gonococcal infections in at risk women in the Kumasi metropolis, Ghana. Ghana Med J. 2010;44(1):21-4.

22. Agyarko-Poku T. P3-S7. 18 Aetiological agents of infective vaginal discharge among women attending a STD clinic in Kumasi, Ghana. Sex Transm Infect. 2011;87(Suppl 1):A305.

23. Abraha M, Egli-Gany D, Low N. Epidemiological, behavioural, and clinical factors associated with antimicrobial-resistant gonorrhoea: a review. F1000Res. 2018;7:400.

24. Hutton HE, Mccaul ME, Santora PB, Erbelding EJ. The relationship between recent alcohol use and sexual behaviors: gender differences among STD clinic patients. Alcohol Clin Exp Res. 2008;32(11):2008-15.

25. Kongnyuy EJ, Wiysonge CS. Alcohol use and extramarital sex among men in Cameroon. BMC international health and human rights. 2007;7(1):6.

26. Kalichman SC, Pellowski J, Turner C. Prevalence of sexually transmitted co-infections in people living with HIV/AIDS: systematic review with implications for using HIV treatments for prevention. Sexually transmitted infections. 2011;87(3):183-90.

27. Nyarko CC, Unson C, Nyarko PK, Koduah M. Chlamydia trachomatis prevalence in Ghana-A study at a municipal district in Western Ghana. International Journal of Scientific \& Technology Research. 2014;3(1):163-9.

\section{Ready to submit your research? Choose BMC and benefit from:}

- fast, convenient online submission

- thorough peer review by experienced researchers in your field

- rapid publication on acceptance

- support for research data, including large and complex data types

- gold Open Access which fosters wider collaboration and increased citations

- maximum visibility for your research: over $100 \mathrm{M}$ website views per year

At BMC, research is always in progress.

Learn more biomedcentral.com/submissions 